Seminar Nasional Teknologi Informasi dan Kedirgantaraan (SENATIK)

Vol. II, 26 November 2016, ISSN: 2528-1666

\title{
RANCANG BANGUN TURBIN ANGIN SAVONIUS 200 WATT
}

\author{
Daniel Teguh Rudianto ${ }^{1}$, Nurfi Ahmadi ${ }^{2}$ \\ ${ }^{1}$ Program Studi Teknik Elektro, ${ }^{2}$ Program Studi Teknik Mesin, Sekolah Tinggi Teknologi Adisutjipto \\ Jl. Janti Blok R LanudAdisutipto, Yogyakarta \\ daans_tr@yahoo.co.id \\ Abstract
}

\begin{abstract}
This study aimed to establish the type of Savonius wind turbines that capable of generating electric power of 200 Watts. This objective relates to Bantul District Government program which plans to build wind turbin generating electrical power (PembangkitListrik Tenaga Bayu, PLTB) 200 Watt as a backup power source for powering cooling fish caught by fishermen in the southern coast. Savonius Turbine chosen with consideration that it has simple construction so that the cost is not expensive, not depending on the direction of the wind, and is suitable for small power plants.

Design of Savonius turbine blade has been completed, the turbine blade height $168 \mathrm{~cm}$ and a diameter of $55 \mathrm{~cm}$. Blade turbine mounted on an arm along $55 \mathrm{~cm}$ from the turbine shaft and separate $120^{\circ}$. The turbine is supported by a 3-foot-tall turbines framework 2,5 $\mathrm{m}$ iron box $4 \mathrm{~cm} \times 4 \mathrm{~cm}$. The test simulated to determine the turbine rotation has been performed at varying wind speeds, i.e. $2 \mathrm{~m} / \mathrm{s}$, $4 \mathrm{~m} / \mathrm{s}$ and $6 \mathrm{~m} / \mathrm{s}$.

Based on test results, the turbine is capable of rotating an average of 54,2 rpm at a wind speed of $2 \mathrm{~m} / \mathrm{s} ; 86,8 \mathrm{rpm}$ at a wind speed of $4 \mathrm{~m} / \mathrm{s}$; and $124,2 \mathrm{rpm}$ at a wind speed of $6 \mathrm{~m} / \mathrm{s}$. These test results indicate that the Savonius turbines can be used to drive a generator producing the need of electrical energy.
\end{abstract}

Keywords: Savonius turbine, electricity generating, wind speed.

\section{Pendahuluan}

\subsection{Latar Belakang Masalah}

Negara Indonesia, sebagai negara maritim, memiliki sumber kekayaan alam kelautan yang luar biasa besar dan apabila dikelola dengan baik akan mampu meningkatkan penghasilan negara dari sektor kelautan. Salah satu caranya adalah dengan memberdayakan para nelayan untuk meningkatkan hasil tangkapan ikan melalui peningkatan fasilitas perahu dan kemudahan dalam memperoleh bahan bakarnya. Namun muncul kendala lain yaitu bagaimana para nelayan mampu menyimpan dan mengawetkan ikan-ikan hasil tangkapan tanpa ada suplai energi listrik untuk menyalakan kotak-kotak pendingin ikan.

Permasalahan yang harus segera diatasi adalah bagaimana menyediakan perangkat pembangkit listrik yang mampu menyediakan daya cadangan untuk menyalakan kotak pendingin ikan. Salah satu solusinya adalah dengan membuat Pembangkit Listrik Tenaga Bayu (PLTB) yang menghasilkan daya sesuai dengan kebutuhan pendinginan ikan, yaitu sekitar 200 watt (untuk 2 kotak pendingin) dengan bahan yang mudah didapat di pasar atau toko setempat. Model turbin angin yang dipilih adalah model Savonius dengan pertimbangan kesederhanaan desain, sesuai untuk daerah dengan kecepatan angin yang rendah (3-5 m/s), dan bekerja selama ada angin yang bertiup tanpa menghiraukan arah datangnya angin. Ukuran turbin, yaitu diameter dan tinggi sudu-sudu turbin, akan ditentukan pada tahap perancangan melalui metode parameter awal sehingga mengurangi waktu dan biaya pembuatannya.

Penelitian ini diharapkan menjadi langkah awal dari pengembangan PLTB berdaya 200 watt yang sangat mungkin akan diproduksi secara masal apabila faktor teknis dan biaya pembuatannya terpenuhi. Rancang bangun PLTB 200 watt ini direncakan akan dikembangkan dan dilanjutkan 
dengan dana penelitian skema hibah yang lain, yaitu penelitian hibah bersaing (HIBER), dan atau penelitian antar perguruan tinggi (PEKERTI).

\subsection{Perumusan Masalah}

Penelitian tentang rancang bangun turbin Savonius dan analisa kinerjanya telah banyak dilakukan, namun belum ada yang secara spesifik membahas rancang bangun turbin Savonius dengan daya 200 Watt. Permasalahan yang dihadapi saat ini adalah bagaimana rancang bangun turbin angin yang mudah dibuat dengan harga yang terjangkau, serta mampu memenuhi kebutuhan listrik untuk menyalakan kotak pendingni ikan sebesar 200 Watt. Ukuran menjadi salah satu pertimbangan utama perancangan turbin. Ukuran turbin diharapkan tidak terlalu besar sehingga tidak memakan tempat yang luas, dan harus pada ketinggian yang aman karena putaran turbin dapat berbahaya baik bagi anak-anak maupun orang dewasa.

Penentuan tinggi dan diameter sudu-sudu turbin, jumlah sudu, serta bentuk kurva sudu turbin merupakan masalah yang harus diatasi dalam perancangan turbin. Parameter-parameter dimensi turbin akan berpengaruh pada kinerja turbin, yaitu kecepatan putaran dan torsi yang dihasilkan.

Desain struktur turbin juga berperan penting dalam menentukan keberhasilan penelitian ini, walaupun bukan sebagai obyek utama penelitian. Struktur turbin harus dibuat kokoh sedemikian rupa sehingga tidak terjadi goncangan yang terlalu keras pada saat turbin berputar.

\subsection{Kajian Pustaka}

Sistem pembangkit listrik tenaga angin menggunakan kincir angin sumbu vertikal untuk beban rumah tinggal, dengan diameter $60 \mathrm{~cm}, 36$ sudu menghasilkan putaran sebesar $229 \mathrm{rpm}$, torsi $7,19 \mathrm{Nm}$, dan daya 63,65 Watt pada kecepatan angin $1,45 \mathrm{~m} / \mathrm{s}$. Kincir dengan diameter $80 \mathrm{~cm} 36 \mathrm{sudu}$ menghasilkan putaran sebesar 205,30 rpm, torsi 6,44 $\mathrm{Nm}$, dan daya 41,12 Watt [1].

Pada kinerja Turbin Angin Poros Vertikal Dengan Modifikasi Rotor Savonius L Untuk Optimasi Kinerja Turbin, putaran turbin akan naik sejalan dengan pengurangan sudut kelengkungan dan penambahan kecepatan angin. Turbin yang memiliki putaran paling besar adalah turbin dengan sudut kelengkungan sebesar $20^{\circ}$ dan putaran paling kecil terdapat pada turbin dengan sudut kelengkungan yang paling besar, yaitu pada sudut $80^{\circ}$ [2].

Pada perbandingan kinerja turbin Savonius 2 sudu dengan 3 sudu. Disimpulkan bahwa tubin Savonius dengan jumlah sudu 3 akan membangkitkan torsi dan daya listrik pada kecepatan angin yang lebih rendah $(1,8 \mathrm{~m} / \mathrm{s})$ dibandingkan dengan turbin 2 sudu, dan menghasilkan daya yang lebih besar pada kecepatan angin yang sama [3].

Pengujian turbin angin Savonius tipe U tiga sudu di Pantai Air Tawar Padang, menyimpulkan bahwa putaran maksimum rotor adalah $196 \mathrm{rpm}$ pada kecepatan angin 7,9m/s, besar daya 126 watt. Untuk putaran minimum rotor $53 \mathrm{rpm}$ pada kecepatan angin $2,7 \mathrm{~m} / \mathrm{s}$ tidak mampu menghasilkan daya karena putaran pada poros alternator setelah melewati sistem transmisi menjadi $156 \mathrm{rpm}$ sehingga tidak mampu membangkitkan listrik, dimana spesifikasi alternator yang dipakai baru mampu menghasilkan listrik jika putaran besar dari 300rpm [4].

Turbin Angin Savonius memiliki karakteristik hubungan antara kecepatan angin, tinggi dan diameter turbin dengan daya dan kecepatan putaran rotor yang dihasilkan. Pada kecepatan angin yang sama, semakin besar tinggi dan diameter turbin akan semakin besar pula daya yang dihasilkan namun putaran rotor justru semakin kecil. Dapat dikatakan bahwa tinggi dan diameter turbin berbanding lurus dengan daya yang dihasilkan, sedangkan kecepatan putaran rotor berbanding terbalik dengan diameter turbin [5].

\section{Metode Penelitian}

\subsection{Tahapan Penelitian}

Tahapan penelitian yang akan dilakukan adalah sebagai berikut :

1. Studi literatur, yaitu dengan mempelajari beberapa referensi yang mampu menunjang untuk melakukan penelitian. Referensi yang digunakan antara lain bersumber dari bukubuku, artikel, sumber dari internet, serta sumbersumber lain yang berhubungan dengan rancang bangun turbin Savonius.

2. Metode eksperimen, yaitu melakukan penelitian dengan membuat model turbin angin tipe Savonius 3 sudu dengan dimensi sesuai rentang kinerja yang dikehendaki, yaitu untuk kecepatan angin $3 \mathrm{~m} / \mathrm{s}$ sampai dengan $17 \mathrm{~m} / \mathrm{s}$. 
3. Model turbin diuji secara simulasi untuk mengetahui besar kecepatan putaran turbin yang dihasilkan pada kecepatan angin $2 \mathrm{~m} / \mathrm{s} ; 4 \mathrm{~m} / \mathrm{s}$; dan $6 \mathrm{~m} / \mathrm{s}$.

4. Analisa hasil pengujian turbin angindilakukan untuk mengetahui unjuk kerjanya dan upayaupaya mengatasi kekurangan yang terjadi pada rancangan turbin.

\subsection{Instrumen Penelitian}

Peralatan yang digunakan dalam penelitian ini adalah sebagai berikut :

a. Besi pejal 11/4" untuk poros turbin.

b. Drum plastik untuk sudu-sudu turbin.

c. Besi kotak $4 \mathrm{~cm} \mathrm{x} 4 \mathrm{~cm}$ untuk rangka turbin.

d. Besi kotak $2 \mathrm{~cm} \times 2 \mathrm{~cm}$ untuk rangka sudu-sudu turbin.

e. Besi siku $3 \mathrm{~cm}$ x $3 \mathrm{~cm}$ untuk rangka turbin.

$f$. Bearing untuk bantalan poros turbin.

g. Baut dan mur.

\subsection{Prosedur Penelitian}

a. Pengerjaan rangka penyangga turbin.

b. Pengerjaan komponen-komponen turbin.

c. Penyambungan dan pemasangan komponenkomponen turbin.

d. Pengujian mekanis turbin angin.

e. Analisa data hasil pengujian.

f. Penulisan laporan

\subsection{Diagram Alir Penelitian}

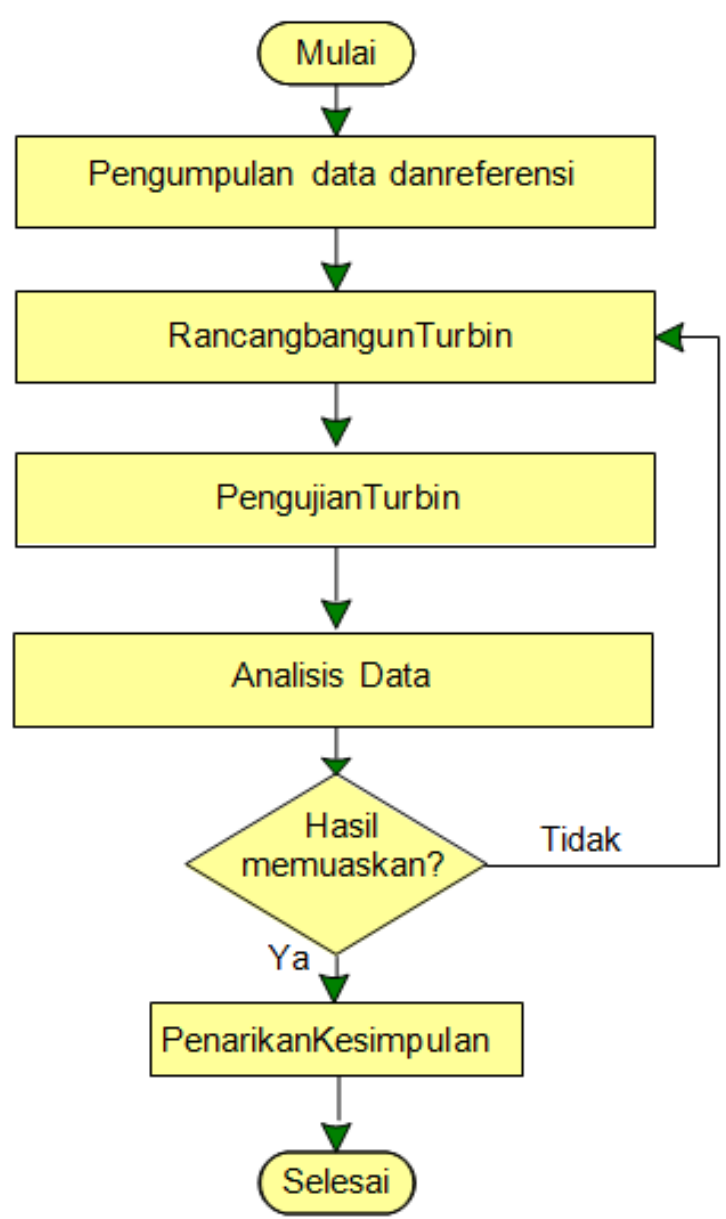

Gambar 1. Diagram alir penelitian 


\section{Hasil dan Pembahasan}

\subsection{Hasil rancang bangun turbin Savonius}

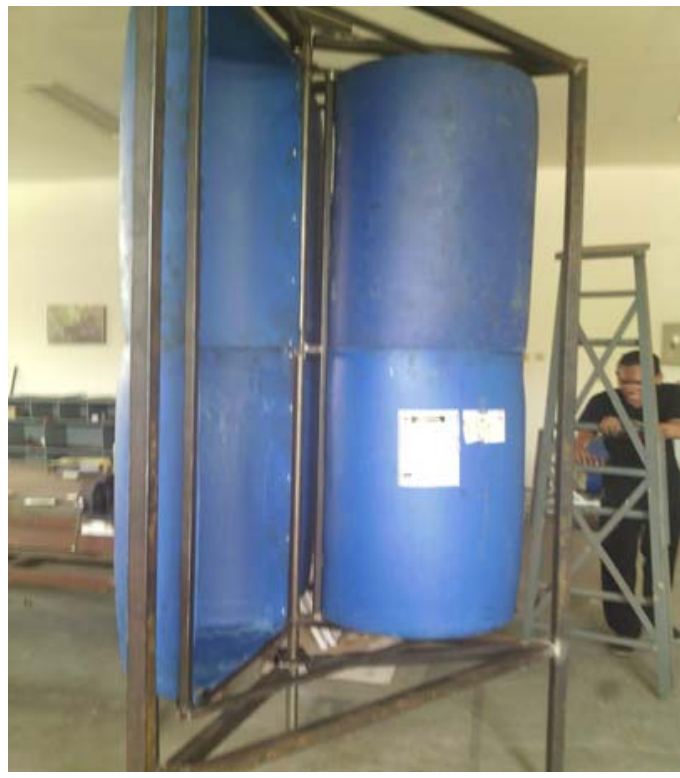

Gambar 2. Turbin hasil perancangan

\subsection{Hasil Pengujian}

Putaran turbin yang dihasilkan pada pengujian untuk kecepatan angin $\mathrm{V}=2 \mathrm{~m} / \mathrm{s}, \mathrm{V}=4 \mathrm{~m} / \mathrm{s}$, dan $\mathrm{V}=6$ $\mathrm{m} / \mathrm{s}$ disajikan pada Tabel 4.1 di bawah ini.

Tabel 4.1. Putaran turbin yang dihasilkan dalam pengujian.

\begin{tabular}{|c|c|c|c|}
\hline \multirow{2}{*}{$\begin{array}{c}\text { Pengujian } \\
\text { No. }\end{array}$} & \multicolumn{3}{|c|}{ Putaran Turbin per menit (rpm) } \\
\cline { 2 - 4 } & $\mathrm{V}=2 \mathrm{~m} / \mathrm{s}$ & $\mathrm{V}=4 \mathrm{~m} / \mathrm{s}$ & $\mathrm{V}=6 \mathrm{~m} / \mathrm{s}$ \\
\hline 1 & 54 & 86 & 123 \\
\hline 2 & 54 & 87 & 124 \\
\hline 3 & 55 & 87 & 124 \\
\hline 4 & 56 & 88 & 125 \\
\hline 5 & 54 & 87 & 126 \\
\hline 6 & 53 & 85 & 126 \\
\hline 7 & 55 & 86 & 125 \\
\hline 8 & 54 & 87 & 122 \\
\hline 9 & 53 & 88 & 122 \\
\hline 10 & 54 & 87 & 125 \\
\hline Rata-rata & 54,2 & 86,8 & 124,2 \\
\hline
\end{tabular}

\subsection{Pembahasan}

Daya teoritis dihitung pada kecepatan angin $B_{n}=2 \mathrm{~s} / \mathrm{d} 10$, atau $2,5 \mathrm{~m} / \mathrm{s}$ s $/ \mathrm{d} 26 \mathrm{~m} / \mathrm{s}$. Untuk menghindari kerusakan, pada kecepatan $B_{n}>10$, turbin harus dihentikan. Perhitungan daya diperoleh dengan persamaan daya teoritis [6]:

$P=-\frac{1}{2} \rho A\left[C_{d 1}(V-C)^{2} C-C_{d 2}(V+C)^{2} C\right]$

di mana $C=0,7 \mathrm{~V} ; \rho=1,204 \mathrm{~kg} / \mathrm{m} 3$,

jika dimasukkan ke dalam persamaan (1) diperoleh persamaan daya:

$P=-0,5.1,204 . A\left[C_{d 1}(V-C)^{2} C-C_{d 2}(V+C)^{2} C\right]$

Selanjutnya dengan memasukkan nilai-nilai: $C_{d l}=2,3: C_{d 2}=1,2$ dan $C=0,7 \mathrm{~V}$ diperoleh:

$P=-0,602 \cdot A\left(0,283 V^{3}-1,828 V^{3}\right)$

$P_{\text {Teoritis }}=0,93 \cdot A \cdot V^{3}$

Perhitungan rancang bangun didasarkan pada daya efektif, yaitu daya aktual yang dihasilkan oleh turbin. Daya aktual adalah daya teoritis yang dipengaruhi oleh efisiensi mekanis turbin. Jadi

$P_{\text {aktual }}=\eta_{m} \cdot P_{\text {Teoritis }}$

Efisiensi mekanis dianggap sebesar 85\% maka besar $P_{\text {aktual }}$ bisa dihitung berdasarkan persamaan (4) dan (5):

$\mathrm{P}_{\text {aktual }}=0,85 \cdot 0,93 \cdot \mathrm{A} \cdot \mathrm{V}^{3}$

$P_{\text {aktual }}=0,79 \cdot A \cdot V^{3}$

Berdasarkan hasil pengujian di atas maka dapat dihitung secara teoritis besarnya daya yang dihasilkan turbin, dengan asumsi bahwa efisiensi mekanis turbin $85 \%$ :

$P_{\text {aktual }}=0,79 \cdot A \cdot V^{3}$

Dengan $P_{\text {aktual }}$ adalah daya aktual yang dihasilkan turbin (Watt), $A$ adalah dimensi total sudu-sudu turbin $\left(\mathrm{m}^{2}\right)$, dan $V$ adalah kecepatan angin $(\mathrm{m} / \mathrm{s})$. 
Dengan tinggi sudu-sudu turbin $1,68 \mathrm{~m}$ dan diameter $0,55 \mathrm{~m}$, maka luasan total sudu-sudu turbin yang berjumlah 3 buah adalah $2,77 \mathrm{~m}^{2}$. Hubungan daya aktual turbin dengan dimensi turbin dan kecepatan angin dapat dinyatakan:

1. Kecepatan angin $2 \mathrm{~m} / \mathrm{s}$, maka daya aktual:

$$
\begin{aligned}
P_{\text {aktual }} & =0,79 \cdot 2,77 \cdot 2^{3} \\
& =17,51 \mathrm{Watt}
\end{aligned}
$$

2. Kecepatan angin $4 \mathrm{~m} / \mathrm{s}$, maka daya aktual:

$$
\begin{aligned}
P_{\text {aktual }} & =0,79 \cdot 2,77 \cdot 4^{3} \\
& =140,05 \mathrm{Watt}
\end{aligned}
$$

3. Kecepatan angin $6 \mathrm{~m} / \mathrm{s}$, maka daya aktual:

$$
\begin{aligned}
P_{\text {aktual }} & =0,79 \cdot 2,77 \cdot 6^{3} \\
& =472,67 \mathrm{Watt}
\end{aligned}
$$

\section{Kesimpulan}

Berdasarkan hasil perancangan dan pengujian yang telah dilakukan terhadap model turbin Savonius, maka dapat ditarik kesimpulan:

1. Turbin dapat dibuat dengan bahan yang murah dan mudah didapatkan dari pasar lokal.

2. Rancangan turbin cukup sederhana sehingga bisa dikerjakan dalam waktu yang relatif singkat, yaitu 2 hari.

3. Turbin berputar dengan kecepatan 54,2 putaran per menit pada kecepatan angin $2 \mathrm{~m} / \mathrm{s} ; 86,8$ putaran per menit pada kecepatan angin $4 \mathrm{~m} / \mathrm{s}$; dan 124,2 putaran per menit pada kecepatan angin $6 \mathrm{~m} / \mathrm{s}$.

4. Hasil perhitungan secara teoritis, turbin akan menghasilkan daya aktual sebesar 17,51 Watt pada $\mathrm{V}=2 \mathrm{~m} / \mathrm{s} ; 140,05$ Watt pada $\mathrm{V}=4 \mathrm{~m} / \mathrm{s}$; dan 472,67 Watt pada $\mathrm{V}=6 \mathrm{~m} / \mathrm{s}$.

5. Hasil pengujian dan perhitungan menunjukkan bahwa turbin akan mampu menghasilkan daya listrik lebih dari 200 Watt pada kecepatan angin $6 \mathrm{~m} / \mathrm{s}$.

\section{Saran}

1. Desain turbin perlu dikembangkan dengan menambah jumlah sudu-sudu turbin agar mendapatkan daya aktual yang besar pada kecepatan angin yang rendah.

2. Pada penelitian berikutnya, turbin digandeng dengan generator untuk menghasilkan tenaga listrik.

\section{Ucapan Terima kasih}

Penulis mengucapkan terima kasih kepada Kemenristik Dikti yang telah memberi dukungan finansial terhadap penelitian ini melalui skema hibah Penelitian Dosen Pemula tahun 2016.

\section{DAFTAR PUSTAKA}

[1] Mochammad M.R., dkk., 2013, Sistem Pembangkit Listrik Tenaga Angin Menggunakan Kincir Angin Sumbu Vertikal Untuk Beban Rumah Tinggal, $14^{\text {th }}$ Seminar on Inteligent Technology and It's Applications, Institut Teknologi Sepuluh November Surabaya, 16 Mei 2013

[2] Marizka L.D., 2010, Analisis Kinerja Turbin Angin Poros Vertikal Dengan Modifikasi Rotor Savonius L Untuk Optimasi Kinerja Turbin, Skripsi, Fakultas MIPA Universitas SEbelas Maret Surakarta.

[3] Zulfikar dkk, 2011,Kajian Eksperimental Pengaruh Jumlah Sudu Terhadap Torsi Dan Putaran Turbin Savonius Type U, Jurnal Teknik Mesin Politeknik Negeri Padang, Vol. 8, No. 2, Desember 2011.

[4] Sumiati, R., 2012, Pengujian Turbin Angin Savonius Tipe U Tiga Sudu Di Lokasi Pantai Air Tawar Padang, Jurnal Teknik Mesin Politeknik Negeri Padang, Vol. 1, No. 1, Juni 2012.

[5] Rudianto, Daniel T., 2013, Analisa Karakteristik Turbin Angin Savonius Menggunakan Metode Parameter Awal, Laporan Penelitian Internal STTA, Yogyakarta.

[6] Hau, Erich, 2005, Wind Turbin: Fundamentals, Technologies, Application and economic, (diterjemahkan dalam bahasa Inggris oleh : Horst Von Renouard), edisi ke-2, Springer : Berlin, Germany. 